\title{
Burkitt and Burkitt-Like Lymphomas: a Systematic Review
}

\author{
Khalil Saleh $^{1}$ - Jean-Marie Michot ${ }^{2} \cdot$ Valérie Camara-Clayette $^{3} \cdot$ Yegor Vassetsky $^{4} \cdot$ Vincent Ribrag $^{1,2}$
}

(C) Springer Science+Business Media, LLC, part of Springer Nature 2020

\begin{abstract}
Purpose of Review Burkitt's lymphoma and its leukemic form (Burkitt cell acute lymphoblastic leukemia) are a highly aggressive disease. We review the classification, clinical presentation, histology, cytogenetics, and the treatment of the disease.

Recent Findings Burkitt's lymphoma might be associated with tumor lysis syndrome which is a potentially fatal complication that occurs spontaneously or upon initiation of chemotherapy. Major improvements were made in the treatment of pediatric and adults population using short-course dose-intensive chemotherapy regimens, usually 1 week after a prephase induction. Addition of Rituximab to chemotherapy has become a standard of care. Relapsed/refractory disease has a very poor prognosis and the benefit from autologous/allogeneic hematopoietic stem cell transplant remains uncertain.

Summary Rituximab-based short-course dose-intensive chemotherapy is the standard of care of Burkitt's lymphoma even in the immunodeficiency-related form.
\end{abstract}

Keywords Burkitt's lymphoma $\cdot$ L3ALL $\cdot$ Sporadic form $\cdot$ Endemic form · Immunodeficiency-related $\cdot$ C-MYC $\cdot$ T $(8 ; 14)$. Tumor lysis syndrome $\cdot$ CODOX-M/IVAC $\cdot$ LMB $\cdot$ GMALL-B-ALL/NHL $\cdot$ hyperCVAD $\cdot$ DA-EPOCH-R $\cdot$ HOVON

\section{Introduction}

Burkitt's lymphoma (BL) is a highly aggressive B cell non-Hodgkin lymphoma (NHL) which is initially described by Denis Burkitt in 1958 [1]. It derives from mature germinal or post germinal center B cell and is divided into three clinical entities, all of which present rearrangements of the MYC oncogene contributing to overexpression of c-myc and associated with the fastest growing human tumor with a doubling time between 24 to $48 \mathrm{~h}$ [2]. BL may present as a leukemic form corresponding to Burkitt cell acute lymphoblastic leukemia (L3ALL)

This article is part of the Topical Collection on Lymphomas

Vincent Ribrag

vincent.ribrag@gustaveroussy.fr

1 Département d'Hématologie, Institut de Cancérologie Gustave Roussy, 114 Rue Edouard Vaillant, 94810 Villejuif, France

2 DITEP, Institut de Cancérologie Gustave Roussy, Villejuif, France

3 Plateforme AMMICA, Recherche Translationnelle Hématologie, INSERM US23/CNRS UMS3655, Gustave Roussy, Université Paris Sud, Institut de Cancérologie Gustave Roussy, Villejuif, France

4 Centre National de la Recherche Scientifique (CNRS) UMR 9018, Université Paris Sud, Institut de Cancérologie Gustave Roussy, Villejuif, France according to the revised 2016 World Health Organization (WHO) classification of hematologic malignancies. Three aggressive $\mathrm{B}$ cell neoplasms that mimic BL were distinguished by the WHO classification: "Burkitt-like lymphoma with 11q aberration," "Highgrade B cell lymphoma with MYC and BCL2 and/or BCL6 rearrangement," and "High-grade B cell lymphoma, not otherwise specified" [3•]. Overall, BL represents less than $5 \%$ of lymphoma cases in adults; however, it accounts for $40 \%$ of all childhood NHL [4]. BL in childhood is associated with improved outcome with survival rates higher than $90 \%$ even in patients with central nervous system (CNS) involvement or L3ALL using briefduration, high intensity chemotherapy regimens. In adults, recent data reported an overall survival (OS) rate exceeding $70 \%[5 \bullet \cdot]$. In this paper, we review the classification, epidemiology, clinical presentation, histopathology, and the treatment of BL.

\section{Classification and Epidemiology}

According to the WHO classification, three different entities of BL have been identified with similar morphology, immunophenotype, and genetic features: endemic, sporadic (predominant variant diagnosed in non-malarial areas), and 
immunodeficiency-related [6]. The endemic type occurs mainly in areas of holoendemic malaria in Africa and Papua New Guinea/Irian jaya and is associated with EBV in almost all cases [7]. Endemic BL is highly prevalent and the annual incidence has been estimated at 4-5 per 100,000 children younger than 18 years per year in equatorial Africa [8]. In this region, endemic BL accounts for $50 \%$ of all childhood tumor diagnoses and up to $90 \%$ of lymphoma diagnoses. The peak of incidence is between 4 and 7 years and occurs mainly in males with male to female ratio of $2: 1[9,10]$. The sporadic variant is diagnosed predominantly in Western Europe, North America, and East Asia classified as low-risk areas. No specific demographic association was described with sporadic BL and it is less commonly (10-20\%) associated with EBV infection. Sporadic BL represents 1 to $2 \%$ of adult lymphomas and 30 to $40 \%$ of pediatric NHL in North America and Western Europe. The annual incidence is 2 to 3 cases per million per year $[11,12]$. Sporadic BL occurs most commonly in younger patients with a peak incidence at the age of 11 years in children and at the age of 30 in adults; it is 3.5 times more common in men than in women $[7,13]$. The immunodeficiencyrelated form is mainly observed in patients with HIV infection. Before the era of highly active retroviral therapy (HAART), BL represented 25 to $40 \%$ of patients diagnosed with HIVassociated NHL and was 1000 times more frequent in HIVpositive patients than in uninfected people. EBV was found in less than $40 \%$ of patients HIV-associated BL in US and European patients [14-16]. HIV-associated BL has similar characteristics as sporadic BL in terms of stage, CNS involvement, bone marrow involvement, and histology [17, 18]. It frequently occurs when CD4 T cell counts are above 200 cells $/ \mu 1$ [19]. However, diffuse large B cell lymphoma which is the most common HIV-associated NHL (45\% of patients) and plasmablastic lymphoma which represents 3 to $12 \%$ of HIV-associated NHL occur especially when CD4 T cell counts are less than 200 cells $/ \mu$ l. Primrary cerebral lymphoma was observed with CD4 T cell counts less than 100 cells $/ \mu l$ [20]. The risk of developing BL following organ transplantation increases four to 5 years after the procedure but is still much less than in HIV-infected individuals [21]. The annual incidence of immunodeficiency-associated BL in the USA is 22 per 100,000 person-years [19].

\section{Clinical Presentation}

$\mathrm{BL}$ often presents as a rapidly growing tumor and is characterized by a very short doubling time between 24 and $48 \mathrm{~h}$ and a quick dissemination to extranodal sites including CNS and bone marrow. Almost $70 \%$ of newly diagnosed patients have an advanced stage III or IV disease at the diagnosis [6]. BL at the time of diagnosis might be associated with spontaneous tumor lysis syndrome (TLS) which requires early transfer to intensive care unit (ICU) [22]. Table 1 resumes the clinical presentation of BL/L3ALL.

Endemic and sporadic forms differ concerning the primary tumor sites. The abdomen is the most frequent site of presentation of the sporadic form of BL and seen in 60 to $80 \%$ of patients followed by the head and neck [12]. The most common presenting symptoms of the abdominal involvement are abdominal pain, nausea, vomiting, gastrointestinal bleeding and distention. Involvement of the jaw or facial bones is not common in the sporadic form. At the time of initial diagnosis, $30 \%$ and $15 \%$ of patients respectively present bone marrow and CNS involvement [23]. The most common site of presentation of the endemic form is the facial skeleton and mainly the jaw which is present in $50 \%$ of cases and more common in young patients (peak ages of incidence 3 to 7 years). Fifteen percent of patients present with sudden paraplegia and incontinence. CNS involvement is found in 30 to $40 \%$ of patients at the time of BL diagnosis; however, bone marrow infiltration is rare and is found in less than $10 \%$ of patients [23,24]. Patients with immunodeficiency-associated forms often present signs and symptoms related to their immunodeficiency and nodal involvement with an increased risk for CNS dissemination.

\section{Histology and Immunocytochemistry}

BL is characterized by an extremely high proliferation index (almost 100\%) with a high turnover associated with a high apoptosis rate. The cells are intermediate in size, with deeply basophilic cytoplasm containing small vacuoles and round nuclei with granular chromatin and dark nucleoli with frequent mitoses. Some nuclear pleiomorphism is observed due to some plasmacytoid and atypical variants. BL is also characterized by the "starry-sky" appearance: the "sky" represented by the background of basophilic tumor cells and the "stars" being the numerous interspersed tangible body macrophages (histiocytes), with a large clear cytoplasm, that have ingested apoptotic cells (Fig. 1). The cells are always CD20 and CD79a positive and express germinal center-associated markers (CD10 and BCL6). These cells are generally negative for BCL2 as well as terminal deoxynucleotidyl transferase (TdT) [25].

\section{Cytogenetics and Molecular Biology}

The translocation $(8 ; 14)(\mathrm{q} 24 ; \mathrm{q} 32)$ is the most common chromosomal translocation occurring in $80 \%$ of BL. This translocation concerns the long arm of chromosome 8 , the site of the MYC oncogene (8q24) and the immunoglobulin heavy chain locus on chromosome 14 . The $t(2 ; 8)$ and $t(8 ; 22)$, which correspond to the kappa and lambda light chain loci on chromosomes 2 and 22, are found in $15 \%$ and $5 \%$ of patients, 
Table 1 Clinical presentations of BL/L3ALL

\begin{tabular}{|c|c|c|c|}
\hline & Endemic & Sporadic & Immunodeficiency-related \\
\hline Incidence & $3-6$ per $10^{5}$ children/year & $\begin{array}{l}2-3 \text { per } 10^{6} \text { subjects/year } 30 \% \text { of } \\
\text { pediatric NHL } 1 \% \text { of adult NHL }\end{array}$ & $\begin{array}{l}30 \% \text { of HIV-associated NHL CD4 } \\
\quad+>0.2 \times 10^{9} / 1\end{array}$ \\
\hline Age & Children > >adults, mainly males 4-7 years & Children $>$ adults & Adults \\
\hline Localization & Extra nodal, jaw (50\%) & Extra nodal, mainly the gut, jaw ( $25 \%)$ & $\begin{array}{l}\text { Frequently extra nodal } \\
\text { (gut, bone marrow) }\end{array}$ \\
\hline Bone marrow infiltration & $<10 \%$ & $30 \%$ & $20-60 \%$ \\
\hline CNS involvement & $30-40 \%$ & $15 \%$ & $20-30 \%$ \\
\hline EBV & $>90 \%$ & $20 \%$ & $20-40 \%$ \\
\hline c-myc & Identical in all types & Identical in all types & Identical in all types \\
\hline
\end{tabular}

CNS central nervous system, EBV Epstein-Barr Virus, NHL non-Hodgkin lymphoma, HIV Human Immunodeficiency Virus, Identical in all types: $80 \%$ $\mathrm{t}(8 ; 14), 15 \% \mathrm{t}(2 ; 8), 5 \% \mathrm{t}(8 ; 22)$

respectively [26]. Following translocation, the constitutive overexpression of the MYC oncogene is found in all patients with BL. Many of the cases that were previously categorized as BL in the absence of a MYC rearrangement are currently classified as the new provisional "Burkitt-like lymphoma with 11q aberration" entity.

Many somatic mutations were found in patients with BL using the next generation sequencing. For example, mutations of the transcription factor TCF3 or its negative regulator ID3 (DNA binding protein family) were detected in 70\%, 67\%, and $40 \%$ of patients with sporadic, endemic, and HIVassociated BL respectively [26].

\section{Treatment of Burkitt's Lymphoma}

The approaches that showed improved results in children were rapidly proposed to adults. The initial treatment consisted of a "pre phase" induction therapy with low doses of steroids and chemotherapy that reduces the risk of fatal TLS. TLS should be anticipated with ICU admission and "preventive" hemodialysis of patients presenting with renal failure and high uric

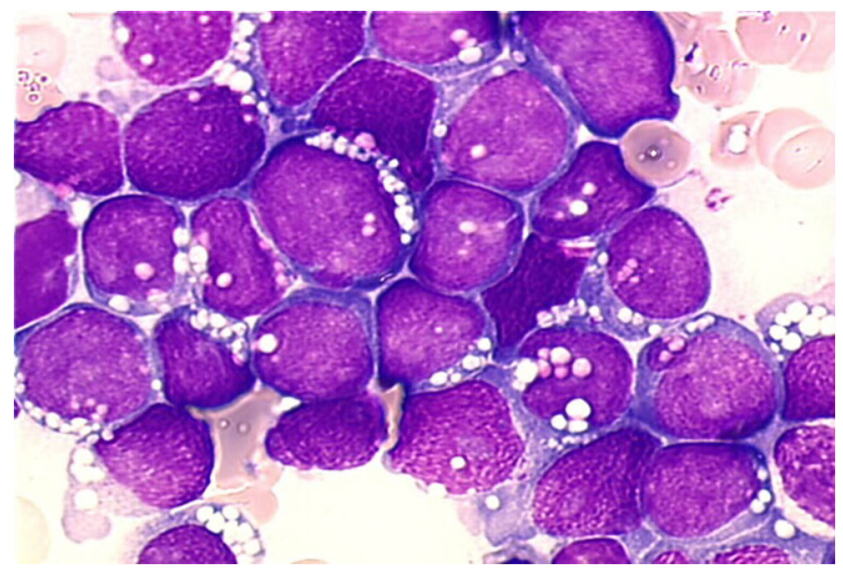

Fig. 1 BL cells, with basophilic cytoplasm, round nuclei with coarse chromatin, multiple nucleoli, and several cytoplasmic vacuoles acid levels. Rasburicase administration and aggressive hydration are mandatory.

\section{Treatment of Burkitt's Lymphoma in Children}

Classical lymphoma regimens using anthracyclines, vincristine (VCR), cyclophosphamide (CPM), and prednisone with CNS prophylaxis were initially used for the treatment of children with BL/ L3 acute lymphoblastic leukemia (L3ALL), but failed to achieve complete response (CR) in advanced disease [27].

The St. Jude's group, French SFOP, and German BFM group improved survival rates in children with BL by introducing the "pre phase" combining low doses of steroids and chemotherapy (CPM, VCR) to prevent the onset of potentially lethal TLS followed by high-dose chemotherapy 1 week later. Treatment protocols consisted of fractionated high doses of CPM (or ifosfamide), intermediate or high dose (HD) MTX and $\mathrm{Ara} \mathrm{C}$, and teniposide or etoposide in addition to doxorubicin and VCR. CNS treatment was gradually intensified with HD MTX (at $5 \mathrm{~g} / \mathrm{m} 2$ in BFM trials and $8 \mathrm{~g} / \mathrm{m} 2$ in SFOP trials), a greater number of triple intrathecal injections (with Ara C, MTX, hydrocortisone), consolidation with etoposide and HD Ara C, and cranial irradiation [28-30]. Table 2 resumes the results of the major protocols used in the treatment of children with BL/ALL or advanced B cell lymphomas.

\section{Treatment of Adults with Burkitt's Lymphoma}

Table 3 resumes the major protocols for the treatment of adults with HIV-negative BL. The CODOX-M/IVAC regimen, also called Magrath regimen, was initially developed at the National Cancer Institute in the 1980s for the treatment of aggressive NHL. The CODOX-M/IVAC consisted of cyclophosphamide, doxorubicin, vincristine/ ifosfamide, cytarabine, and etoposide. Mead et al. reported the results of an international multicenter phase II trial for the treatment of 
Table 2 Major protocols for the treatment of children with BL/ALL or advanced B-cell lymphomas

\begin{tabular}{|c|c|c|c|c|c|c|c|c|}
\hline Regimen & $\begin{array}{l}\text { Number } \\
\text { of patients }\end{array}$ & $\begin{array}{l}\text { Median } \\
\text { age (years) }\end{array}$ & Stage III/IV/ALL (\%) & $\mathrm{CNS}+(\%)$ & $\mathrm{CR}$ rate $(\%)$ & OS rate $(\%)$ & EFS rate $(\%)$ & $\begin{array}{l}\text { Toxic } \\
\text { death }(\%)\end{array}$ \\
\hline LMB81 [44] & 114 & 8 & 100 & 21 & 84 & 67 & DFS: 64 & 10 \\
\hline LMB84 [28] & 216 & 5.5 & 93 & 0 & 94 & 79 & 78 & 6 \\
\hline HiC-COM [45] & 20 & 8 & 100 & 10 & 95 & - & 2-year: 75 & - \\
\hline LMB89 [29] & 561 & 8 & 79 & 12 & 97 & 5-year: 92.5 & 5-year: 91 & 1 \\
\hline NHL-BFM86 [46] & 302 & 8.8 & 73 & 4 & - & - & 7 -year: 80 & 4 \\
\hline NHL-BFM90 [30] & 413 & 9 & 60 & 1 & - & - & 89 & 3 \\
\hline UKCCSG 9003[47] & 63 & 8.4 & 100 & 56 & - & 69 & 69 & 11 \\
\hline FAB/LMB96 [48] & 201 & - & - & 43 & - & 4-year: 82 & 4-year: 79 & 5 \\
\hline $\begin{array}{l}\text { COG ANHL01P1 } \\
\text { (with Rituximab) [49] }\end{array}$ & 45 & 11 & 100 & 0 & - & - & 3 -year: 93 & 0 \\
\hline $\begin{array}{l}\text { COG ANHL01P1 } \\
\text { (with Rituximab) [50] }\end{array}$ & 40 & 11 & 100 & 38 & - & 3 -year: 90 & 3 -year: 90 & 5 \\
\hline
\end{tabular}

$C N S$ central nervous system, $O S$ overall survival, $C R$ complete response, EFS event free survival

patients with BL using the International Prognostic indexbased criteria [31]. Patients with low risk disease defined by a combination of the following criteria: normal LDH level, WHO performance status of 0 or 1, Ann Arbor stage I or II, and no tumor mass $\geq 10 \mathrm{~cm}$ were treated with 3 cycles of modified CODOX-M. All remaining patients are considered high risk and received 4 cycles of alternating modified CODOX-M and IVAC chemotherapy. Fifty-two patients with confirmed histological BL were enrolled of whom 12 patients had a low risk disease and 40 patients had a high risk disease. Median age of the entire cohort was 35 years (range 1560 years). Forty patients (77\%) presented CR and 5 patients (10\%) partial response (PR). Overall 2-year event-free survival (EFS) rate was $64.6 \%$ (95\% CI 50.4-78.9\%) and 2-year OS rate $72.8 \%$ (95\% CI $59.4-86.3 \%$ ). The 2-year EFS rate in patients with low risk disease was $83.3 \%$ (95\% CI 59.0 to $99.0 \%$ ) and was $59.5 \%$ (95\% CI 43.0 to $76.0 \%$ ) in patients with high risk disease. The 2-year OS rate in patients with low risk disease $81.5 \%$ (95\% CI 56.1 to $99.0 \%$ ) and was $69.9 \%$ (95\% CI 52.3 to $87.5 \%$ ). All patients had treatment-related grade 3-4 neutropenia. Patients with low risk disease received a median number of 0 platelets unit (range 0-25) and a median number of 17 days with IV antibiotics while patients with high risk disease required a median number of 8.5 platelets unit (range 0-90) and a median number of 19 days of IV antibiotics [31]. More recently, 53 patients with BL were treated with CODOX-M/IVAC regimen in a prospective, international, non-randomized phase 2 trial: eleven patients were treated

Table 3 Major protocols for the treatment of adults with HIV-negative BL/ALL

\begin{tabular}{|c|c|c|c|c|c|c|c|}
\hline Regimen & $\begin{array}{l}\text { Number } \\
\text { of patients }\end{array}$ & $\begin{array}{l}\text { Median } \\
\text { age }\end{array}$ & $\begin{array}{l}\text { Stage III/IV/ } \\
\text { ALL }(\%)\end{array}$ & $\mathrm{CNS}+(\%)$ & $\begin{array}{l}\mathrm{CR} \text { rate } \\
(\%)\end{array}$ & OS rate $(\%)$ & EFS rate $(\%)$ \\
\hline $\begin{array}{l}\text { CODOX-M/IVAC UKLG } \\
\text { LY06 Trial }\end{array}$ & 52 & 35 & 61 & 10 & 76.5 & 1-year: 75 2-year: 72.8 & 1-year: 69.2 2-year: 64.6 \\
\hline $\begin{array}{l}\text { CODOX-M/IVAC MRC/NCRI } \\
\text { LY10 trial }\end{array}$ & 53 & 37 & 76 & 11 & - & 2-year: 67 & 2-year PFS: 64 \\
\hline DA-EPOCH-R & 19 & 25 & 58 & 5 & - & 100 & 95 \\
\hline R-HyperCVAD & 31 & 46 & ALL: 45 & 7 & 86 & 3-year: 89 & 3-year: 80 \\
\hline R-HyperCVAD & 57 & 44 & ALL: 47 & - & 94 & 5-year: 74 & - \\
\hline LM BA-02 & 226 & 47 & 62 & 25 & - & $\begin{array}{l}\text { 3-year: } 83 \% \text { in rituximab } \\
\text { arm vs } 70 \% \text { in } \\
\text { placebo arm }\end{array}$ & $\begin{array}{l}\text { 3-year: } 75 \text { in rituximab } \\
\text { arm vs } 62 \% \text { in } \\
\text { placebo arm }\end{array}$ \\
\hline GMALL-B-ALL/NHL2002 & 363 & 42 & 71 & 10 & 88 & 80 & PFS: $71 \%$ \\
\hline HyperCVAD [51] & 26 & 58 & ALL: 100 & 42 & 81 & & 3-year DFS: 61 \\
\hline $\begin{array}{l}\text { Modified LMB without rituximab } \\
\text { [52] }\end{array}$ & 72 & 33 & 73 & 15 & 72 & 2-year: 70 & 2 -year: 65 \\
\hline
\end{tabular}

$C N S$ central nervous system, $O S$ overall survival, $C R$ complete response, $E F S$ event free survival, $P F S$ progression-free survival, $D F S$ disease-free survival 
with 3 cycles of dose-modified CODOX-M and 42 patients were treated with 4 cycles of alternating dose-modified CODOX-M/IVAC. The 2-year progression-free survival (PFS) was $64 \%$ (95\% CI 51-77\%) and the 2-year OS was $67 \%$ (95\% CI $54-80 \%$ ) [32].

Dunleavy et al. reported the outcome of 19 patients with HIV-negative BL treated with a standard dose adjusted combination (DA-EPOCH-R) [33]. The regimen combined etoposide, doxorubicin, cyclophosphamide, vincristine, prednisone, and rituximab. Patients received CNS prophylaxis with 8 doses of intrathecal methotrexate. The median age of this group of patients was 25 years (range 15-88 years). Five patients $(26 \%)$ were more than 40 years old and 11 patients (58\%) had Ann Arbor stage III or IV disease. After a median follow-up of 86 months, the rate of progression-free survival was $95 \%$ (95\% CI 75 to $99 \%$ ) and an OS rate of $100 \%$ (95\% CI 82 to $100 \%$ ). None of the patients died from BL. The incidence of neutropenia was $52 \%$. Only one patient presented CNS involvement which can explain the absence of high-dose MTX in the treatment regimen [33]. Thomas et al. reported the experience of the MD Anderson Cancer Center using chemoimmunotherapy with HyperCVAD plus rituximab for the treatment of adult BL or ALL in a phase II trial. Rituximab $375 \mathrm{mg} / \mathrm{m}^{2}$ was given on days 1 and 11 of HyperCVAD courses and on days 1 and 8 of MTX and cytarabine courses. The dose of cytarabine was reduced from 3 to $1 \mathrm{~g} / \mathrm{m}^{2}$ in patients aged $\geq 60$ years to avoid cerebellar neurotoxicity. CNS prophylaxis alternated intrathecal (IT) MTX $12 \mathrm{mg}$ on day 2 and cytarabine $100 \mathrm{mg}$ on day 7 of each courses (a total of 16 IT). Therapeutic radiation therapy was done if patients presented cranial nerve palsies or intracranial mass. Thirty one patients with newly diagnosed BL (17 patients $(55 \%)$ ) or ALL (14 patients (45\%)) were treated. The median age was 46 years old (range 17-77 years) of whom 9 patients (29\%) had more than 60 years old. Fifteen patients $(48 \%)$ only presented Burkitt morphology while 16 patients (52\%) presented Burkitt-like morphology. CR was observed in 24 of 28 evaluable patients (86\%); three patients had a PR and one patient a resistant disease. No induction death was reported. The 3-year OS, EFS, and disease-free survival were $89 \%$, $80 \%$, and $88 \%$ respectively. With a median follow-up of 22 months, 2 of 28 patients (7\%) relapsed. Grade 3 to 4 myelosuppression occurred in all patients and was expected. Dose reduction of MTX or cytarabine was observed in 17 of 30 patients $(57 \%)$. The multivariate analysis of the results and historical data (HyperCVAD without rituximab) groups identified age and treatment with rituximab as favorable factors [34]. The update of the series was presented at the ASH 2011 meeting with 26 additional patients. Overall, 57 patients with newly diagnosed HIV-negative BL (30 patients) or B-ALL (27 patients) were analyzed. The median age was 44 years (range $17-77$ years) of whom $25 \%$ were aged 60 years or older. The overall CR rate was $94 \%$ in 47 evaluable patients.
After a median follow-up of 62 months, 4 patients relapsed. The 5-year OS rate was $74 \%$. Six patients presented secondary myelodysplasia [35].

Ribrag et al. reported the results of the large-scale randomized, controlled, open-label, phase III trial which evaluated the addition of rituximab to the dose-dense malignant B cell lymphoma (MBL) regimen in adults older than 18 years old with HIV-unrelated BL including patients with Burkitt's leukemia from 45 hematological centers in France [5•]. Patients were stratified into 2 groups according to disease extension: absence (group B) or presence (group C) of bone marrow or CNS involvement. Then, patients in group $\mathrm{C}$ were also stratified based on age and CNS involvement. Participants were randomized to either rituximab and dose-dense chemotherapy or chemotherapy alone. Rituximab $\left(375 \mathrm{mg} / \mathrm{m}^{2}\right)$ was administered on days 1 and 6 during the first 2 courses for a total of 4 infusions. Patients who did not achieve a CR after the first cycle of cytarabine and MTX were candidates for high-dose chemotherapy followed by autologous stem cell transplantation (ASCT). Two hundred sixty patients were enrolled (124 patients in group B of whom 60 patients were randomized in the rituximab arm and 136 patients in group $\mathrm{C}$ of whom 70 patients received rituximab). Cranial irradiation (18 Grays) was delivered only to patients with CNS dissemination. After a median follow-up of 38 months, patients in the rituximab arm had a significantly higher 3-year EFS rate $(75 \%$ vs $62 \%, p=0.024)$. The 3 -year OS in the rituximab group was $83 \%$ versus $70 \%$ in the control group $(p=0.011)$. The hazard ratio (HR) was 0.59 for EFS (95\% CI $0.38-0.94 ; p=0.025$ ) and 0.51 for OS ( $95 \% \mathrm{CI} 0.30-0.86 ; p=0.012$ ). There was no significant difference in terms of adverse events between the two groups. The most frequent adverse events were infectious and hematological events [5•].

The GMALL-B-ALL/NHL2002 is the largest prospective multicenter non-randomized trial which evaluated the efficacy of the addition of rituximab to chemotherapy for the treatment of patients with adult Burkitt's lymphoma/leukemia [36]. Patients aged 15 years or more with BL, Burkitt-like lymphoma, atypical Burkitt's lymphoma, or Burkitt's leukemia were eligible. Patients received a prephase treatment with cyclophosphamide and prednisone on days 1 to 5 then received three different courses of 5-day chemotherapy with highdose methotrexate, high-dose cytosine aracytine, cyclophosphamide, etoposide, ifosfamide, corticosteroids, and triple IT given every 2 weeks and repeated once for a total of 6 cycles. Rituximab $375 \mathrm{mg} / \mathrm{m}^{2}$ was given at the beginning of each cycle followed by chemotherapy the next day. Two additional doses of rituximab are given 3 and 6 weeks after the completion of the chemotherapy cycles. Patients older than 55 years received a reduced regimen. CNS radiotherapy is recommended at the dosage of $24 \mathrm{~Gy}$ in patients with initial CNS involvement and mediastinal radiotherapy ( $36 \mathrm{~Gy}$ ) is recommended in patients with initial mediastinal mass $>7.5 \mathrm{~cm}$. Three 
hundred sixty three patients were enrolled of whom 225 patients $(62 \%)$ had BL and 138 patients (38\%) had Burkitt's leukemia. The median age was 42 years (range $16-85$ years). The CR rate of the entire cohort was $88 \%$. The death rate during induction was higher in older patients $(>55$ years) compared with younger patients $(<55$ years) $(11 \%$ vs $2 \%$, $p=0.0002$ ). Deaths were mainly due to infections. The 5year OS was $80 \%$ and 5-year PFS was $71 \%$. The 5-year OS was significantly different between age groups less than 25 years, 26 to 55 , and older than 55 years ( $90 \%$ vs $84 \%$ vs $62 \%$ respectively). Sixty-one patients received radiation therapy, of whom 24 patients were treated with CNS radiation therapy and 6 patients with mediastinal radiation therapy. The overall relapse rate of the CR patients was $12 \%$ (37/ 319). The most frequent site of relapse was the CNS ( $n=$ 12). Grade 3 or 4 neutropenia occurred in $58 \%$ of young patients $(<55$ years) and infections occurred in $38 \%$ of patients after the first cycle [36].

To date, there is no specific regimen to recommend for the treatment of HIV-negative BL due to the lack of comparative randomized trials. The classical treatment is to begin with the prephase with corticosteroids and low-dose chemotherapy (cyclophosphamide and vincristine) followed by the induction treatment on the basis of short-intensive chemotherapy. Our specific approach is based on the LMBA02 protocol which is stratified by age and risk group.

\section{Adolescent and Young Adults Burkitt's Lymphoma}

The definition of adolescent and young adults (AYA) subset is controversial and can be defined as an age range between 15 and 25-40 years according to the upper age limit adopted in different studies which reported age-related results [37] adolescn health med ther 2017). AYA subset is associated with more favorable outcome than older adults. In the GMALL trial, AYAs aged between 15 and 25 years had significant higher OS than adults between 25 and 55 and than older patients (OS $90 \%$ vs $84 \%$ vs $62 \%$ respectively) (GMALL). In the LMBA02 randomized trial regardless of rituximab, EFS and OS of AYAs aged less than 40 years were significantly better than older patients $(p<0.0001)$ (Ribrag).

\section{HIV-Associated Burkitt's Lymphoma}

Cortes et al. described the feasibility and efficacy of the hyperCVAD regimen for the treatment of AIDS-associated Burkitt lymphoma/leukemia [38]. Patients aged $\geq 15$ years with histology-proven diagnosis of Burkitt lymphoma/leukemia, documented HIV infection, and no prior therapy for Burkitt lymphoma/leukemia were included. Thirteen patients were enrolled with a median age of 42 years (range 32-55 years). Seven patients $(50 \%)$ were classified as L3-ALL with bone marrow blasts infiltration $\geq 30 \%$, two other patients had stage
II disease and four other patients stage IV according to Ann Arbor classification. Nine patients received HAART. Three patients had CNS+ involvement. The CR rate was $92 \%$ (12/13 patients). CR occurred after the first cycle in 10 patients. Eight patients continued in $\mathrm{CR}$ after a median of 31 months. The median OS was 12 months and $48 \%$ of patients were alive. Six of seven patients who received HAART at the beginning of the chemotherapy remain in CR after 29 months. The four patients who did not receive HAART died. Grade 3-5 myelosuppression occurred in $100 \%$ of patients and grade 3-4. Twenty six cycles (35\%) were complicated by infections or fever [38].

Dunleavy et al. reported the results of a lower-dose shorter course combination of EPOCH with a double dose of rituximab in 11 patients with HIV-positive BL. Patients did not receive HAART during chemotherapy. Patients received $1 \mathrm{cy}-$ cle after completion of $\mathrm{CR}$ for a minimum of 3 cycles and a maximum of 6 cycles. The median age was 44 years (range 24-60). Nine patients (82\%) had Ann Arbor stage III or IV disease. None of the patients had CNS+ involvement. After a median follow-up of 73 months, the rate of progression-free survival was $100 \%$ (95\% CI 72-100\%) and the rate of OS was $90 \%$ (95\% CI 60-98\%). None of the patients had a recurrence disease or died from BL [33].

AMC 048 (AIDS Malignancy consortium 048) study is the first dedicated phase II clinical trial in patients with HIVassociated BL which aimed to evaluate the feasibility of intensive chemotherapy in the HAART era. In this trial, patients were divided into low-risk disease defined as stage I with a single focus of disease less than $10 \mathrm{~cm}$ and normal lactate dehydrogenase (LDH) or intra-abdominal disease only and total resection and normal LDH after surgery. All other patients were considered to have high risk disease. Low-risk patients were treated with 3 cycles of R-CODOX-M. However, high-risk patients received a total of 4 cycles of RCODOX-M/IVAC/R-CODOX-M/IVAC sequence. Patients with CNS+ disease received IT liposomal cytarabine with CODOX-M cycles and IT methotrexate in the IVAC cycles. A total of 34 patients were enrolled of whom four patients (12\%) had CNS infiltration. Two patients had low-risk disease (6\%). Twenty six patients $(76 \%)$ of patients received HAART at study entry. The median follow-up was 26 months. The 1year PFS was $69 \%$ (95\% confidence interval (CI), 51-82\%). The 1-year OS was $72 \%$ (95\% CI 53-85\%) and the 2-year OS was $69 \%$ (95\% CI 50-82\%). Grade 3-4 toxicity occurred in $79 \%$ of patients. Grade 3-4 hematological toxicity occurred in $59 \%$ of patients (20/34) followed by infectious toxicities $(41 \%)$ and metabolic toxicities $(18 \%)$. Toxic death was observed in 1 patient with encephalopathy, hepatic failure, hepatitis B, and pneumonia $[39 \bullet \cdot]$. There is no specific recommendation for the treatment of HIV-associated BL. The continuation of HAART during chemotherapy has been controversial. 


\section{Autologous Stem Cell Transplantation in First Remission}

There is lack of data supporting the use of high-dose chemotherapy followed by autologous stem cell transplantation (ASCT) in BL patients in first remission. It has been evaluated by the HOVON group and the treatment consisted of two sequential high-dose chemotherapies incorporating prednisone, cyclophosphamide, doxorubicin, etoposide, and mitoxantrone without high-dose MTX and high-dose cytarabine. Patients with at least PR went on BEAM and ASCT. Twenty seven patients with Burkitt or Burkitt-like lymphoma were enrolled. The 5-year OS rate was $81 \%$ and the 5-year EFS was 73\% [40]. In addition, another report of 27 patients who received ASCT had 3-year EFS of $42 \%(95 \%$ CI $27-57 \%$ ) and 3-year OS of 45\% (95\% CI 29-61\%) [41].

\section{Relapsed and Refractory Burkitt's Lymphoma}

Patients with relapsed or refractory BL have a very poor prognosis and the salvage treatment is generally unsuccessful. Autologous stem cell transplantation (ASCT) might be an option. In fact, a retrospective analysis from the European Group for Blood and Marrow transplantation reported a 3year OS rate of $37 \%$ in patients with chemosensitive disease and $7 \%$ in patients with resistant disease following ASCT [42]. Allogeneic SCT may be considered in relapsing patients with a sibling or matched related donor who may not be eligible for or may have previously received an autologous SCT. Five-year PFS is around 27\% and treatment-related morbidity is high [43]. Novel agents might be evaluated for the treatment of BL according to the new genomic findings (TCF3, ID3, CCND3) such as PI3K inhibitors, inhibitors of CDK6, and MYC inhibitors. Chimeric Antigen Receptor T cells (CAR T cells) which has been approved for the treatment of ALL should be tested in patients with relapsed/refractory BL given its biologic similarity to ALL. The CARPALL study is a phase I clinical trial evaluating CD19+ Chimeric Antigen Receptor $\mathrm{T}$ cells in children and young adults (less than 24 years) with high risk, relapsed CD19+ heamatological malignancies (ALL and BL) (NCT02443831).

\section{Conclusion}

BL is a highly aggressive, chemo-sensitive NHL that requires diagnosis and treatment in expert centers. Nowadays, rapid establishment of a short intensive course of chemoimmunotherapy with CNS-oriented therapy and aggressive prevention and treatment of TLS yields excellent outcomes in young "fit" patients. Despite the improvements in $\mathrm{CR}$ and survival rates, many challenges remain, particularly in the treatment of certain patient groups such as immunocompromised and elderly individuals as well as the treatment of relapsed/refractory disease. Targeting PI3K pathway and MYC and TCF3 expression, cell cycle kinases are among many therapeutic options to be tested in future clinical trials.

\section{Compliance with Ethical Standards}

Conflict of Interest Khalil Saleh declares that he has no conflict of interest.

Jean-Marie Michot has served as an investigator of clinical studies funded by Celgene and Bristol-Myers Squibb.

Valérie Camara-Clayette declares that she has no conflict of interest.

Yegor Vassetsky declares that he has no conflict of interest.

Vincent Ribrag has received research funding from argenx, has received compensation from Gilead, Infinity, MSD, Bristol-Myers Squibb, Epizyme, NanoString, Incyte, Roche, and AstraZeneca for participation on advisory boards, and has received compensation from Servier for service as a consultant.

Human and Animal Rights and Informed Consent This article does not contain any studies with human or animal subjects performed by any of the authors.

\section{References}

Papers of particular interest, published recently, have been highlighted as:

- Of importance

•• Of major importance

1. Burkitt D. A sarcoma involving the jaws in African children. Br J Surg. 1958;46:218-23.

2. Casulo C, Friedberg JW. Burkitt lymphoma- a rare but challenging lymphoma. Best Pract Res Clin Haematol. 2018;31:279-84.

3. Swerdlow SH, Campo E, Pileri SA, Harris NL, Stein H, Siebert R, et al. The 2016 revision of the World Health Organization classification of lymphoid neoplasms. Blood. 2016;127:2375-90. The aim of this revised version of the WHO classification is to incorporate the new scientific and clinical information to refine diagnostic criteria for previously described lymphomas.

4. Bishop PC, Rao VK, Wilson WH. Burkitt's lymphoma: molecular pathogenesis and treatment. Cancer Investig. 2000;18:574-83.

5.• Ribrag V, Koscielny S, Bosq J, Leguay T, Casasnovas O, Fornecker L-M, et al. Rituximab and dose-dense chemotherapy for adults with Burkitt's lymphoma: a randomised, controlled, open-label, phase 3 trial. Lancet. 2016;387:2402-11. This is the first and only phase III trial in Burkitt's lymphoma evaluating the efficacy of the addition of rituximab to standard dose-dense chemotherapy for the treatment of adults with Burkitt's lymphoma. The authors showed that rituximab improved outcomes.

6. Jaffe ES. The 2008 WHO classification of lymphomas: implications for clinical practice and translational research. Hematology Am Soc Hematol Educ Program. 2009:523-31.

7. Molyneux EM, Rochford R, Griffin B, Newton R, Jackson G, Menon G, et al. Burkitt's lymphoma. Lancet. 2012;379:1234-44.

8. Orem J, Mbidde EK, Lambert B, de Sanjose S, Weiderpass E. Burkitt's lymphoma in Africa, a review of the epidemiology and etiology. Afr Health Sci. 2007;7:166-75. 
9. Magrath I. Epidemiology: clues to the pathogenesis of Burkitt lymphoma. Br J Haematol. 2012;156:744-56.

10. Mwanda OW, Rochford R, Moormann AM, Macneil A, Whalen C, Wilson ML. Burkitt's lymphoma in Kenya: geographical, age, gender and ethnic distribution. East Afr Med J. 2004:S68-77.

11. Sant M, Allemani C, Tereanu C, De Angelis R, Capocaccia R, Visser O, et al. Incidence of hematologic malignancies in Europe by morphologic subtype: results of the HAEMACARE project. Blood. 2010;116:3724-34.

12. Mbulaiteye SM, Biggar RJ, Bhatia K, Linet MS, Devesa SS. Sporadic childhood Burkitt lymphoma incidence in the United States during 1992-2005. Pediatr Blood Cancer. 2009;53:366-70.

13. Armitage JO, Weisenburger DD. New approach to classifying nonHodgkin's lymphomas: clinical features of the major histologic subtypes. Non-Hodgkin's Lymphoma Classification Project. J Clin Oncol. 1998;16:2780-95.

14. Knowles DM. Etiology and pathogenesis of AIDS-related nonHodgkin's lymphoma. Hematol Oncol Clin North Am. 2003;17: 785-820.

15. Martínez-Maza O, Breen EC. B-cell activation and lymphoma in patients with HIV. Curr Opin Oncol. 2002;14:528-32.

16. Beral V, Peterman T, Berkelman R, Jaffe H. AIDS-associated nonHodgkin lymphoma. Lancet. 1991;337:805-9.

17. Davi F, Delecluse HJ, Guiet P, Gabarre J, Fayon A, Gentilhomme $\mathrm{O}$, et al. Burkitt-like lymphomas in AIDS patients: characterization within a series of 103 human immunodeficiency virus-associated non-Hodgkin's lymphomas. Burkitt's Lymphoma Study Group JCO. 1998;16:3788-95.

18. Spina M, Tirelli U, Zagonel V, Gloghini A, Volpe R, Babare R, et al. Burkitt's lymphoma in adults with and without human immunodeficiency virus infection: a single-institution clinicopathologic study of 75 patients. Cancer. 1998;82:766-74.

19. Guech-Ongey M, Simard EP, Anderson WF, Engels EA, Bhatia K, Devesa SS, et al. AIDS-related Burkitt lymphoma in the United States: what do age and CD4 lymphocyte patterns tell us about etiology and/or biology? Blood. 2010;116:5600-4.

20. Ferry JA. Burkitt's lymphoma: clinicopathologic features and differential diagnosis. Oncologist. 2006;11:375-83.

21. Massey EW, Moore J, Schold SC. Mental neuropathy from systemic cancer. Neurology. 1981;31:1277-81.

22. Blum KA, Lozanski G, Byrd JC. Adult Burkitt leukemia and lymphoma. Blood. 2004;104:3009-20.

23. Magrath IT. African Burkitt's lymphoma. History, biology, clinical features, and treatment. Am J Pediatr Hematol Oncol. 1991;13: $222-46$.

24. Falini B, Fizzotti M, Pileri S, Liso A, Pasqualucci L, Flenghi L. Bcl6 protein expression in normal and neoplastic lymphoid tissue. Ann Oncol. 1997;8:S101-4.

25. Casulo C, Friedberg J. Treating Burkitt lymphoma in adults. Curr Hematol Malig Rep. 2015;10:266-71.

26. Dunleavy K, Little RF, Wilson WH. Update on Burkitt lymphoma. Hematol Oncol Clin North Am. 2016;30:1333-43.

27. Murphy SB, Bowman WP, Abromowitch M, Mirro J, Ochs J, Rivera G, et al. Results of treatment of advanced-stage Burkitt's lymphoma and B cell (SIg+) acute lymphoblastic leukemia with high-dose fractionated cyclophosphamide and coordinated highdose methotrexate and cytarabine. J Clin Oncol. 1986;4:1732-9.

28. Patte C, Philip T, Rodary C, Zucker JM, Behrendt H, Gentet JC, et al. High survival rate in advanced-stage B-cell lymphomas and leukemias without CNS involvement with a short intensive polychemotherapy: results from the French Pediatric Oncology Society of a randomized trial of 216 children. J Clin Oncol. 1991;9:123-32.

29. Patte C, Auperin A, Michon J, Behrendt H, Leverger G, Frappaz D, et al. The Société Française d'Oncologie Pédiatrique LMB89 protocol: highly effective multiagent chemotherapy tailored to the tumor burden and initial response in 561 unselected children with B-cell lymphomas and L3 leukemia. Blood. 2001;97:3370-9.

30. Reiter A, Schrappe M, Tiemann M, Ludwig WD, Yakisan E, Zimmermann $\mathrm{M}$, et al. Improved treatment results in childhood B-cell neoplasms with tailored intensification of therapy: a report of the Berlin-Frankfurt-Münster Group Trial NHL-BFM 90. Blood. 1999;94:3294-306.

31. Mead GM, Sydes MR, Walewski J, Grigg A, Hatton CS, Pescosta $\mathrm{N}$, et al. An international evaluation of CODOX-M and CODOX-M alternating with IVAC in adult Burkitt's lymphoma: results of United Kingdom Lymphoma Group LY06 study. Ann Oncol. 2002;13:1264-74.

32. Mead GM, Barrans SL, Qian W, Walewski J, Radford JA, Wolf M, et al. A prospective clinicopathologic study of dose-modified CODOX-M/IVAC in patients with sporadic Burkitt lymphoma defined using cytogenetic and immunophenotypic criteria (MRC/ NCRI LY10 trial). Blood. 2008;112:2248-60.

33. Dunleavy K, Pittaluga S, Shovlin M, Steinberg SM, Cole D, Grant C, et al. Low-intensity therapy in adults with Burkitt's lymphoma. N Engl J Med. 2013;369:1915-25.

34. Thomas DA, Faderl S, O'Brien S, Bueso-Ramos C, Cortes J, Garcia-Manero G, et al. Chemoimmunotherapy with hyperCVAD plus rituximab for the treatment of adult Burkitt and Burkitt-type lymphoma or acute lymphoblastic leukemia. Cancer. 2006;106:1569-80.

35. Paper: Hyper-CVAD and rituximab for De Novo Burkitt lymphoma/leukemia [Internet]. [cited 2019 Nov 7]. Available from: https://oncology.by/uplds/ASH/MAC/webprogramcd/ Paper45001.html

36. Hoelzer D, Walewski J, Döhner H, Viardot A, Hiddemann W, Spiekermann K, et al. Improved outcome of adult Burkitt lymphoma/leukemia with rituximab and chemotherapy: report of a large prospective multicenter trial. Blood. 2014;124:3870-9.

37. Dozzo M, Carobolante F, Donisi PM, Scattolin A, Maino E, Sanchetta R, et al. Burkitt lymphoma in adolescent and young adults: management challenges. Adolesc Health Med Ther. 2017;8:11-29.

38. Cortes J, Thomas D, Rios A, Koller C, O'Brien S, Jeha S, et al. Hyperfractionated cyclophosphamide, vincristine, doxorubicin, and dexamethasone and highly active antiretroviral therapy for patients with acquired immunodeficiency syndrome-related Burkitt lymphoma/leukemia. Cancer. 2002;94:1492-9.

39.• Noy A, Lee JY, Cesarman E, Ambinder R, Baiocchi R, Reid E, et al. AMC 048: modified CODOX-M/IVAC-rituximab is safe and effective for HIV-associated Burkitt lymphoma. Blood. 2015;126:160-6. This phase II trial showed also the efficacy of the addition of rituximab for the treatment of HIV-associated Burkitt's lymphoma.

40. van Imhoff GW, van der Holt B, MacKenzie MA, Ossenkoppele GJ, Wijermans PW, Kramer MHH, et al. Short intensive sequential therapy followed by autologous stem cell transplantation in adult Burkitt, Burkitt-like and lymphoblastic lymphoma. Leukemia. 2005;19:945-52.

41. Song KW, Barnett MJ, Gascoyne RD, Horsman DE, Forrest DL, Hogge DE, et al. Haematopoietic stem cell transplantation as primary therapy of sporadic adult Burkitt lymphoma. Br J Haematol. 2006;133:634-7.

42. Sweetenham JW, Pearce R, Taghipour G, Blaise D, Gisselbrecht C, Goldstone AH. Adult Burkitt's and Burkitt-like non-Hodgkin's lymphoma-outcome for patients treated with high-dose therapy and autologous stem-cell transplantation in first remission or at relapse: results from the European Group for Blood and Marrow Transplantation. JCO. 1996;14:2465-72.

43. Maramattom LV, Hari PN, Burns LJ, Carraeras J, ArceseW, Cairo MS, et al. Autologous and allogeneic transplantation for burkitt lymphoma outcomes and changes in utilization: a report from the 
center for international blood and marrow transplant research. Biol Blood Marrow Transplant 2013;19:173-9.

44. Patte C, Philip T, Rodary C, Bernard A, Zucker JM, Bernard JL, et al. Improved survival rate in children with stage III and IV B cell non-Hodgkin's lymphoma and leukemia using multi-agent chemotherapy: results of a study of 114 children from the French Pediatric Oncology Society. J Clin Oncol. 1986;4:1219-26.

45. Schwenn MR, Blattner SR, Lynch E, Weinstein HJ. HiC-COM: a 2month intensive chemotherapy regimen for children with stage III and IV Burkitt's lymphoma and B-cell acute lymphoblastic leukemia. J Clin Oncol. 1991;9:133-8.

46. Reiter A, Schrappe M, Parwaresch R, Henze G, Müller-Weihrich S, Sauter S, et al. Non-Hodgkin's lymphomas of childhood and adolescence: results of a treatment stratified for biologic subtypes and stage-a report of the Berlin-Frankfurt-Münster Group. J Clin Oncol. 1995;13:359-72.

47. Atra A, Gerrard M, Hobson R, Imeson JD, Ashley S, Pinkerton CR. Improved cure rate in children with B-cell acute lymphoblastic leukaemia (B-ALL) and stage IV B-cell non-Hodgkin's lymphoma (B-NHL)-results of the UKCCSG 9003 protocol. Br J Cancer. 1998;77:2281-5.

48. Cairo MS, Gerrard M, Sposto R, Auperin A, Pinkerton CR, Michon $\mathrm{J}$, et al. Results of a randomized international study of high-risk central nervous system B non-Hodgkin lymphoma and B acute lymphoblastic leukemia in children and adolescents. Blood. 2007;109:2736-43.

49. Goldman S, Smith L, Anderson JR, Perkins S, Harrison L, Geyer MB, et al. Rituximab and FAB/LMB 96 chemotherapy in children with stage III/IV B-cell non-Hodgkin lymphoma: a Children's Oncology Group report. Leukemia. 2013;27: 1174-7.

50. Goldman S, Smith L, Galardy P, Perkins SL, Frazer JK, Sanger W, et al. Rituximab with chemotherapy in children and adolescents with central nervous system and/or bone marrow-positive Burkitt lymphoma/leukaemia: a Children's Oncology Group Report. Br J Haematol. 2014;167:394-401.

51. Thomas DA, Cortes J, O'Brien S, Pierce S, Albitar M, et al. HyperCVAD program in Burkitt's-type acute lymphoblastic leukemia. JClin Oncol. 1999; 17:2461-70

52. Diviné M, Casassus P, Koscienly S, Bosq J, Sebban C, Le Maignan C, et al. Burkitt lymphoma in adults: a prospective study of 72 patients treated with an adapted LMB protocol. Ann Oncol. 2005;16:1928-35.

Publisher's Note Springer Nature remains neutral with regard to jurisdictional claims in published maps and institutional affiliations. 